\title{
The effect of timolol drops on respiratory function
}

\section{Abstract}

Purpose Recently, attention has been focused on the adverse drug reactions of topical timolol, especially with regard to respiratory function in the elderly. This study was designed to assess whether timolol causes an alteration in lung function in patients without pre-existing respiratory disease and who have not suffered the impact of long-term $\beta_{2}$ blockade.

Methods A placebo-controlled randomised, double-masked, cross-over study was carried out on 20 ocular hypertensive patients with intraocular pressures over $21 \mathrm{mmHg}$, normal optic discs and full visual fields by Humphrey perimetry. Subjects received single-dose units of timolol maleate $0.5 \%$ drops or normal saline drops. Both were instilled in one eye or systemically (sublingually). The peak expiratory flow rate (PFR), forced expiratory volume (FEV), vital capacity (VC) and FEV/VC $(\%)$ ratio were all measured both before and after each type of drop and route of administration.

Results Two hours after instillation of timolol there was no change in PFR ( $p=0.67)$ or VC $(p=0.40)$, but there was a fall in FEV $(p=0.038)$ and the FEV/VC $(\%)$ ratio $(p=0.041)$. The fall was greatest after topical administration.

Conclusions Our results show that in our group of patients there was a tendency towards mild bronchial obstruction after topical timolol, although this was not clinically significant.

S.A. Vernon

Department of

Ophthalmology

Queen's Medical Centre

Nottingham NG7 2UH, UK

K. Fielding

Trent Institute for Health

Services Research

Queen's Medical Centre

Nottingham, UK

Presented in part at the Glaucoma Society, London, November 1995, and at the Annual Congress of the Royal College of Ophthalmologists, Edinburgh, May 1996
Key words Adverse drug reactions, Bronchoconstriction, Ocular hypertension, Respiratory function, Timolol

Since the introduction of the first topical betablocker (timolol) for use in glaucoma in 1978, this form of therapy has become the commonest medical treatment for the condition. More recently, attention has been focused on the adverse drug reactions of topical timolol, especially with regard to respiratory function in the elderly. ${ }^{1}$ Hence we wanted to assess whether timolol caused an alteration in the lung function of patients who had never previously received ocular hypotensive medication, did not have pre-existing respiratory disease on direct questioning, and who had not suffered the impact of long-term $\beta_{2}$ blockade.

\section{Materials and methods}

A placebo-controlled, randomised, doublemasked, cross-over study was designed to compare the effect on respiratory function of timolol $0.5 \%$ drops given sublingually or systemically (sublingually). The comparison of the effects of these routes of administration on intraocular pressure in 12 ocular hypertensive patients has been reported previously. ${ }^{2}$ On the basis of the data published by Diggory et al., ${ }^{1}$ for this study to have $80 \%$ power to detect a mean change in forced expiratory volume in $1 \mathrm{~s}$ (FEV) of 0.25 with a significance level of $5 \%, 20$ patients were required. ${ }^{2}$

Ethics committee approval was obtained before commencement of the study. After appropriate explanation and informed consent, 20 ocular hypertensive patients (mean age 59.1 years, range $41-87$ years) with intraocular pressure (IOP) over $21 \mathrm{mmHg}$, normal optic discs and full visual fields by Humphrey perimetry, were recruited. Patients were excluded if they were already using topical IOPlowering agents, being treated with systemic beta-blockers or calcium channel blockers, were known to suffer from systemic hypertension, asthma, bronchitis, cardiac failure, sinus bradycardia or heart block, or were smokers.

For each arm of the study, peak expiratory flow rate (PFR), FEV and vital capacity (VC) were measured between 0900 and 0930 hours before instillation of the test drop. From these values, the FEV / VC (\%) ratio was calculated. The four arms, each separated by a minimum of 7 days and performed in random order, consisted of ocular instillation of timolol or placebo, and systemic (sublingual) instillation of timolol or placebo. Ocular instillation was followed by punctal occlusion for $60 \mathrm{~s}$. The systemic drop was placed at the base of the tongue and the patient asked not to swallow for 
Table 1. Comparison of baseline values between the four treatment groups

\begin{tabular}{|c|c|c|c|c|}
\hline Outcome $^{a}$ & & Mean value (SD) & $F$ value (d.f.) & $p$ value \\
\hline VC & $\begin{array}{l}\text { Group } 1 \\
\text { Group } 2 \\
\text { Group } 3 \\
\text { Group } 4\end{array}$ & $\begin{array}{l}3.083(0.922) \\
3.028(0.932) \\
3.042(0.867) \\
3.060(0.871)\end{array}$ & $0.29(3,57)$ & 0.83 \\
\hline FEV & $\begin{array}{l}\text { Group } 1 \\
\text { Group } 2 \\
\text { Group } 3 \\
\text { Group } 4\end{array}$ & $\begin{array}{l}2.490(0.683) \\
2.425(0.658) \\
2.414(0.709) \\
2.452(0.655)\end{array}$ & $0.82(3,57)$ & 0.49 \\
\hline $\mathrm{FEV} / \mathrm{VC}$ & $\begin{array}{l}\text { Group } 1 \\
\text { Group } 2 \\
\text { Group } 3 \\
\text { Group } 4\end{array}$ & $\begin{array}{l}82.47(14.40) \\
82.13(15.05) \\
80.35(12.83) \\
81.72(14.18)\end{array}$ & $0.77(3,57)$ & 0.51 \\
\hline PFR & $\begin{array}{l}\text { Group } 1 \\
\text { Group } 2 \\
\text { Group } 3 \\
\text { Group } 4\end{array}$ & $\begin{array}{l}423.85(106.43) \\
409.80(91.04) \\
401.10(107.52) \\
408.75(109.88)\end{array}$ & $1.14(3,57)$ & 0.34 \\
\hline
\end{tabular}

VC, vital capacity; FEV, forced expiratory volume in $1 \mathrm{~s}$; PFR, peak expiratory flow rate.

${ }^{a}$ Group 1, topical saline; group 2, sublingual saline; group 3, topical timolol; group 4, sublingual timolol.

$30 \mathrm{~s}$. Two hours following drug or placebo, all pretreatment tests were repeated. Each patient attended on four occasions. Two-way analysis of variance and pairwise comparisons using the Bonferroni correction were performed to test for any change in PFR, FEV, VC or FEV/VC (\%) ratio after each of the treatments.

Significance was taken at values of $p \leqslant 0.05$.

One drop from single-dose units of timolol maleate $0.5 \%$ (Glaucol, Baker Norton) or saline $0.5 \%$ (minims, Chauvin), each drop measuring approximately $35 \mu \mathrm{l}$, was used as the medication doses. Both solutions were contained in similar semi-opaque droppers, although the shapes were slightly different. The patients were unaware of which solution they received.

Respiratory function measurements were conducted by the cardiac department at the Queen's Medical Centre using a spirometer (Vitalograph, UK). The technicians were masked to the site and type of drop used for each patient. Randomisation for the cross-over was performed by the picking of folded labels on which were written the site of treatment and solution to be used.

\section{Results}

Twenty patients (11 women, 9 men) completed the four arms of the study. Two-way analysis of variance was used to analyse baseline values (pre-treatment) of the four outcome measures (VC, FEV, FEV/VC and PFR) for the four treatment groups. Results are presented in Table 1. There was no significant difference between the treatment groups regarding baseline values for any of the four outcome measures. Two-way analysis of variance was used to analyse the differences (post-treatment minus pre-treatment) of the four outcome measures for the four treatment groups. Results are presented in Table 2. There was a significant difference between the treatment groups for the outcomes FEV $(p=0.038)$ and FEV/VC $(p=0.041)$, but not for PFR $(p=0.67)$ or VC

Table 2. Comparison of the difference (post-treatment minus pre-treatment) in outcomes between the four treatment groups

\begin{tabular}{|c|c|c|c|c|}
\hline Outcome $^{a}$ & & Mean value (SD) & $F$ value (d.f.) & $p$ value \\
\hline VC & $\begin{array}{l}\text { Group } 1 \\
\text { Group } 2 \\
\text { Group } 3 \\
\text { Group } 4\end{array}$ & $\begin{array}{r}-0.103(0.203) \\
0.016(0.218) \\
-0.033(0.265) \\
-0.079(0.206)\end{array}$ & $1.01(3,57)$ & 0.40 \\
\hline FEV & $\begin{array}{l}\text { Group } 1 \\
\text { Group } 2 \\
\text { Group } 3 \\
\text { Group } 4\end{array}$ & $\begin{array}{r}-0.120(0.182) \\
-0.042(0.209) \\
0.060(0.188) \\
-0.075(0.176)\end{array}$ & $3.00(3,57)$ & 0.038 \\
\hline FEV/VC & $\begin{array}{l}\text { Group } 1 \\
\text { Group } 2 \\
\text { Group } 3 \\
\text { Group } 4\end{array}$ & $\begin{array}{r}-1.628(5.459) \\
-2.053(4.755) \\
3.053(7.629) \\
-0.732(3.202)\end{array}$ & $2.94(3,57)$ & 0.041 \\
\hline PFR & $\begin{array}{l}\text { Group } 1 \\
\text { Group } 2 \\
\text { Group } 3 \\
\text { Group } 4\end{array}$ & $\begin{array}{r}-4.55(30.76) \\
1.25(52.02) \\
11.45(32.86) \\
4.90(42.93)\end{array}$ & $0.52(3,57)$ & 0.67 \\
\hline
\end{tabular}

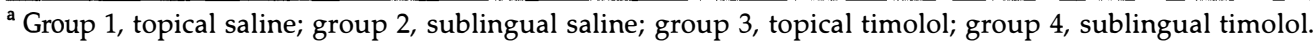


Table 3. Pairwise comparisons

\begin{tabular}{llrr}
\hline Outcome $^{\mathrm{a}}$ & $F$ value (d.f.) & $p$ value $^{\mathrm{b}}$ & Mean and 95\% CI for mean difference $^{\mathrm{c}}$ \\
\hline FEV & & & $-0.180(-0.321,-0.040)$ \\
gp 1 vs gp 3 & $7.27(1,19)$ & 0.014 & $0.034(-0.095,0.162)$ \\
gp 2 vs gp 4 & $0.30(1,19)$ & 0.59 & 0.136 \\
gp 3 vs gp 4 & $6.69(1,19)$ & & $(0.026,0.245)$ \\
FEV / CV & & 0.082 & $-4.680(-10.01,2.54)$ \\
gp 1 vs gp 3 & $3.38(1,19)$ & 0.36 & $-1.320(-4.27,1.63)$ \\
gp 2 vs gp 4 & $0.88(1,19)$ & 0.075 & $3.785 \quad(-0.42,7.99)$ \\
gp 3 vs gp 4 & $3.55(1,19)$ & & $(19)$ \\
\hline
\end{tabular}

${ }^{a}$ Group 1, topical saline; group 2, sublingual saline; group 3, topical timolol; group 4, sublingual timolol.

b To adjust for multiple testing using the Bonferroni correction these $p$ values need to be multiplied by 3 .

${ }^{c}$ Group 1 versus 3: group 1 - group 3; group 2 versus 4: group 2 - group 4; group 3 versus 4: group 3 - group 4.

$(p=0.40)$. Three pairwise comparisons were carried out: treatment group 1 versus 3 , group 2 versus 4 , and group 3 versus 4 . Adjustment of the $p$ values to take into account multiple comparisons is required. Results are presented in Table 3. This shows that there is a significantly greater fall in FEV and FEV/VC when timolol is given topically than when it is given systemically.

\section{Discussion}

The use of beta-blockers is common in many specialities. Indeed, Graft et al. ${ }^{3}$ reported that $1.4 \%$ of patients of all ages were prescribed oral or topical beta-blockers in a 1 year period, and that the frequency of beta-blocker prescriptions increases with patient age. Epidemiological studies have shown that there may be a $37 \%$ prevalence of airway obstruction in the over-65 age group. ${ }^{4}$ It is beyond debate that non-selective beta-blockers should not be used in patients with obstructive airways disease, but despite this $8.9 \%$ of asthmatics aged between 60 and 69 years had received beta-blockers. ${ }^{3}$

Although ophthalmologists should check for contraindications to the use of beta-blockers before a newly diagnosed glaucoma patient is started on such treatment, it is probably less usual for questions to be asked concerning the presence of side effects when the IOPs have been stabilised on beta-blockers, unless the patient volunteers the information. Spaeth and Birbilis ${ }^{5}$ found that less than $10 \%$ of patients admitted adverse reactions to ocular drugs on general questioning, but this increased to over $30 \%$ when mention was made of specific symptoms. As well as adverse drug reactions affecting the respiratory system, there is potential for serious cardiovascular side effects (bradycardia, congestive cardiac failure, arrhythmia, syncope) and central nervous system side effects (depression, hallucination, psychosis, confusion, insomnia, fatigue), ${ }^{6}$ and these probably occur more commonly than ophthalmologists would like to think.

Recent work has highlighted the potential for serious respiratory side effects in the elderly. ${ }^{1}$ Diggory et al. ${ }^{1}$ showed that 19 of 47 elderly patients who were changed from topical timolol to either pilocarpine or betaxolol showed an increase in all of the three indices measured, i.e. PFR, FEV and VC. Although all these results were highly significant on their own, interpretation of the increases in PFR and FEV is less useful without regard to the VC, which usually takes the form of the FEV/VC (\%) ratio. With knowledge of baseline airway function, if the FEV/VC (\%) ratio falls, then this usually indicates an obstructive airways problem. ${ }^{7}$ Returning to the results of Diggory's group, we notice little change in the FEV/VC (\%) ratio, and in fact statistical testing reveals the changes not to be significant. ${ }^{1}$

The side effects of topical timolol in the elderly may be explained by timolol's strong and long-lasting betareceptor antagonism, even after a single dose. ${ }^{8}$ After a $40 \mu$ l dose of timolol $0.25 \%$ in each eye of elderly patients undergoing cataract extraction, timolol was rapidly absorbed into the systemic circulation, occupying up to $68 \%$ of $\beta_{1}$ receptors and up to $87 \%$ of $\beta_{2}$ receptors. The $\beta_{1}$ and $\beta_{2}$ receptor occupancy decreased slowly and was $38 \%$ and $64 \%$ respectively $12 \mathrm{~h}$ after the single dose; the mean half-life was $4.8 \mathrm{~h}$. Both values were twice as high as those found in healthy young volunteers following an intravenous dose of timolol $0.25 \mathrm{mg}$. For the purpose of our study, a separation period of 7 days between each visit was felt to be adequate as we were only using a single rather than a cumulative dose of timolol, and so we did not expect any prolonged beta-receptor antagonism.

Our study does seem to agree with previous work, as our results do show mild respiratory obstruction. The change is mild because there was not a significant fall in PFR but there was a significant fall in the FEV / VC (\%) ratio. $^{7}$ This was the case after the instillation of topical timolol, which is the usual route of administration for glaucoma patients, but not after systemic delivery of timolol. We are unable fully to explain this difference between the two routes of administration. We had expected that any change in respiratory function would be greater after systemic timolol because the sublingual route of administration should lead to the rapid absorption of a higher dose of timolol into the plasma, and it is the plasma timolol that is responsible for the (respiratory and other) side effects. First pass metabolism of timolol by the liver accounts for at least $25 \%$ of an administered oral dose, ${ }^{9}$ and the IOP reductions we obtained after sublingual administration in our original study were probably because maximum plasma levels are obtained rapidly after absorption through the buccal 
mucosa, leading to early receptor blockade before drug metabolism can occur. ${ }^{2}$ This may also account for the fact that these beta-antagonist effects were obtained with a relatively small dose of timolol ( $35 \mu \mathrm{l}$ of a $0.5 \%$ solution) compared with the larger oral doses of timolol used in previous studies.

We tried to reduce the absorption of timolol entering the systemic circulation after ocular instillation (and thus tried to separate local from general effects) by observing strict occlusion of the lacrimal punctum after both the ocular doses. It has previously been shown that systemic drug absorption is reduced (although not abolished) after instillation of topical timolol $0.5 \%$ if the eyes are closed or the lacrimal punctum is occluded. ${ }^{10}$ It would have been ideal in a study such as this to be able to measure the plasma levels of timolol after both the topical and sublingual doses, as well as in patients who may be suffering side effects attributable to timolol.

Unfortunately, the measurement of plasma timolol is difficult, time-consuming and expensive, and is probably beyond the expertise of most clinical ophthalmology departments. These methods have a lower detection limit of timolol of 1-2 $\mathrm{ng} / \mathrm{ml}$, and so levels in patients even after 2 weeks of twice daily timolol $0.5 \%$ may not even be detectable. ${ }^{9,11}$

The above results, although statistically significant, may not necessarily be clinically significant, especially when considering the variability in respiratory function measurements (up to $10 \%$ ). It is reassuring that there was no reduction in PFR, which indicates that there was no intrinsic airway disease. ${ }^{7}$ There was a reduction in the FEV/VC (\%) ratio, indicating mild respiratory obstruction. Much greater reductions in these indices (around 20\%) would be required to have a clinically significant effect on lung function and thus cause a patient to be symptomatic. Certainly none of our study patients reported any respiratory problems on direct questioning at the end of each treatment session.

Our results show that, at least $2 \mathrm{~h}$ after a single dose of topical timolol, and in patients who are otherwise healthy and without pre-existing respiratory problems, there does seem to be a tendency towards bronchial obstruction, although this is not clinically significant. It was also encouraging that there was no bronchoconstriction after systemic timolol. However, this is a small pilot study, and we feel that further investigation into respiratory effects is warranted, in particular to investigate whether long-term usage of beta-blockers induces bronchoconstriction in a similar group of 'low'-risk patients. This should be done with a knowledge of baseline respiratory function before betablockade is initiated. Greater importance should be attached to the identification of the many other adverse reactions of timolol, and similar effort should be made in investigating and reducing these also.

We thank the Cardiac Department at the Queen's Medical Centre for performing all the Vitalographs for our study patients, and Baker Norton pharmaceuticals for the provision of single-dose units of timolol $0.5 \%$ (Glaucol $0.5 \%$ ).

\section{References}

1. Diggory P, Heyworth P, Chau G, McKenzie S, Sharma A, Luke I. Improved lung function tests on changing from topical timolol: non-selective beta-blockade impairs lung function tests in elderly patients. Eye 1993;7:661-3.

2. Sadiq SA, Vernon SA. Sublingual timolol: an alternative to topical medication in glaucoma? $\mathrm{Br} \mathrm{J}$ Ophthalmol 1996;80:532-5.

3. Graft DF, Fowles J, McCoy CE, Lager RA. Detection of $\beta$ blocker use in people with asthma. Ann Allergy 1992;69:449-53.

4. Renwick DS, Connolly MJ. Prevalence and treatment of chronic airways obstruction in older adults. Age Aging 1994;23 (Suppl 2):6.

5. Spaeth G, Birbilis E. The effect of glaucoma and treatment of glaucoma on quality of life. In: Krieglstein E, editor. Glaucoma update, vol IV. Berlin: Springer-Verlag, 1991:2.6-7.

6. Beta-adrenoceptor blocking drugs. In: British national formulary. London: British Medical Association and Royal Pharmaceutical Society of Great Britain, 1995:70-2.

7. Pride NB. Lung function testing. In: Weatherall DJ, Ledingham JGG, Warrell DA, editors. Oxford textbook of medicine, vol 2. New York: Oxford University Press, 1996: 2666-75.

8. Vuori ML, Kaila T. Plasma kinetics and antagonist activity of topical ocular timolol in elderly patients. Graefes Arch Clin Exp Ophthalmol 1995;233:131-4.

9. Alvan G, Calissendorff B, Seideman P, Widmark K, Widmark G. Absorption of ocular timolol. Clin Pharmacokinet 1980;5:95-100.

10. Zimmerman TJ, Kooner KS, Kandarakis AS, et al. Improving therapeutic index of ocular drugs. Arch Ophthalmol 1984;102:551-3.

11. Olah TV, Gilbert JD, Barrish A. Determination of the $\beta$-adrenergic blocker timolol in plasma by liquid chromatography-atmospheric pressure chemical ionization mass spectrometry. J Pharm Biomed Anal 1993;11:157-63. 